\title{
Economic Value of Timely Determination of Unexpected Decreases in Detection of Estrus Using Control Charts ${ }^{1}$
}

\author{
A. de Vries $^{2}$ and B. J. Conlin \\ Department of Animal Science, \\ University of Minnesota, Saint Paul 55108
}

\begin{abstract}
Total economic effects of decreased estrus detection efficiency (EDE) are a function of the economic loss per day and the length of the decrease. A stochastic dynamic dairy herd simulation model was used to determine whether estimates from permanently different EDE rates in herds of 100 and 1000 cows could approximate net returns due to temporary decreases in EDE. The default EDE was $65 \%$ and was either permanently or temporarily decreased to 55,45 , or $35 \%$. Temporary decreases in EDE were assumed to continue until identified using cumulative sum or Shewhart control charts. Marginal changes in net return were greater at lower permanent rates of EDE, with losses ranging from $\$ 0.73$ to 1.24 per extra day open. Temporary decreases in EDE typically yielded smaller effects on net return than permanent decreases, but estimates were not consistently significantly different. However, temporary (30 to $960 \mathrm{~d}$ ) decreases in EDE affected projected herd economic performance for several years after EDE was reset to $65 \%$. Total losses in net return due to temporary decreases in EDE ranged from $\$ 4.44$ (accepting more false alarms) to $\$ 12.53$ (fewer false alarms) per cow for the 100-cow herd. For the 1000-cow herd, total losses in net return ranged from $\$ 0.95$ to 10.43 per cow. Total losses were not dependent on magnitude of decreased EDE because lower EDE could be detected earlier, thereby compensating for higher daily losses; for example, $35 \%$ EDE resulted in lower total losses than 55\% EDE. Decreases to 55\% EDE were detected sooner by cumulative sum charts, whereas decreases to $35 \% \mathrm{EDE}$ were detected earlier by Shewhart charts. Both control charts used together can identify unexpected decreases
\end{abstract}

\footnotetext{
Received April 7, 2003.

Accepted July 8, 2003.

Corresponding author: A. de Vries; e-mail: devries@animal.ufl.edu.

${ }^{1}$ This study was a component of Multi-State Project NC-119, Management Systems for Improved Decision Making and Profitability of Dairy Herds.

${ }^{2}$ Current address: Department of Animal Sciences, University of Florida, Building 459, Shealy Drive, PO Box 110910, Gainesville, FL 32611-0910.
}

in EDE more efficiently, thereby minimizing potential economic losses.

(Key words: detection of estrus, statistical process control, economics, dairy)

Abbreviation key: ATS = average time to signal, cusum = cumulative sum, EDE = estrus detection efficiency, EDR = estrus detection ratio.

\section{INTRODUCTION}

A decrease in estrous detection efficiency (EDE), defined as the proportion of true estruses after the voluntary waiting period observed, is often associated with economic loss (Plaizier et al., 1997). Therefore, an unexpected decrease in EDE should be detected as soon as possible so that corrective action might be taken and the economic loss is minimized (Spahr, 1993).

Total economic loss due to a temporary decrease in EDE depends on the timeliness with which a decrease in EDE is detected and the magnitude of the decrease. Detection of a decrease is not trivial because random variation in the number of observed estruses may obscure the detection of a real decrease. In addition, investigation after a presumed decrease in EDE may be costly and should only be undertaken if there is enough evidence that the decrease in EDE is real and not random.

We studied the performance of various types of statistical process control charts to detect decreases in EDE, as monitored by the estrus detection ratio (EDR) (de Vries and Conlin, 2003). Estrus detection ratio is the ratio of (the number of observed estruses) and (the number of expected estruses times 21). In general, large decreases in EDE were detected earlier than smaller decreases. Large decreases in EDE are also associated with higher losses per day (Oltenacu et al., 1981). Therefore, in this study we provide estimates of the economic value of timely detection of decreases in EDE with Shewhart and cumulative sum (cusum) control charts that monitor EDR.

Control charts are graphs with a center line and an upper and lower control limit. Control limits are placed on the control charts for a desired (target) rate of false 
alarms (alarms or signals while EDE has not changed) based on the random variation in EDR. A control chart is said to signal (alarm) if EDR falls outside a control limit. This indicates that sufficient evidence exists that the rate of EDR has changed to warrant investigation of the cause of the change.

It typically takes time (days to months) before a decrease in EDE is signaled for the first time on a control chart. The duration before a control chart signals a decrease of the same magnitude for the first time varies due to random variation in the number of observed estruses. The standard performance measure of control charts is therefore the average time to first signal (ATS), given a target rate of false alarms that determines the placement of the control limits on the control chart. The ATS, therefore, is the average time between the start of the decrease in EDE and the first signal on a control chart. The ATS will be shorter for larger decreases in EDE and when a higher rate of false alarms is acceptable. In this study we assumed that the EDE was immediately reset to its original rate by herd management when a control chart signaled for the first time.

A temporary decrease in EDE will affect stage of lactation and the frequencies of open and pregnant cows. Consequently, returns and costs are affected for some time. Proper calculation of the changes in returns and costs as a result of different rates of EDE is complex and is therefore best performed using computer simulation (Oltenacu et al., 1981; Marsh et al., 1987; Dijkhuizen and Stelwagen, 1988; Pecsok et al., 1994; and Plaizier et al., 1998). These authors estimated the impact of a one point decrease in $\operatorname{EDE}$ (e.g., from 50 to 49\%) to be anywhere between a gain of more than $\$ 2$ (when EDE was high) to a loss of more than $\$ 17$ (when EDE was already low) in net return per cow per year (Plaizier et al., 1998; adjusted to 2002 dollars). The estimates from these studies differed due to variations in prices, biological functions such as pregnancy rates and lactation curves, insemination and culling policy, and method of calculation.

The aforementioned studies were performed at permanently different rates of EDE (lasting indefinitely), with the implicit assumption that the herds were in steady state. It is not clear if a temporary decrease in EDE (not lasting indefinitely) has similar economic consequences for the herd as can be calculated from a permanent difference of the same magnitude and duration. This is of interest because the total change in net return after an unexpected temporary decrease in EDE is easily calculated using the estimate of the change in net return derived from permanently different rates in EDE and the duration of the decrease. Therefore, our first objective was to investigate whether the change in net return due to a temporary decrease in EDE (temporary estimate) could be approximated by the change in net return derived from a permanent difference of the same magnitude and for the same duration (permanent estimate). Our second objective was to estimate the total change in net return caused by a temporary decrease in EDE until detected by control charts and consequently also the value of earlier detection of a decrease in EDE.

\section{MATERIALS AND METHODS}

\section{Stochastic Dynamic Herd Simulation Model}

All results were obtained with a stochastic dynamic dairy herd simulation model programmed in $\mathrm{C}++$ (de Vries, 2001). The model simulated individual dairy youngstock and cows daily across time and contained functions for milk production, feed intake, disease, reproduction, and cow replacement.

Some of these functions were rather complex through their dependence on many factors. For example, a cow's daily milk production was based on her producing ability, lactation number, DIM, stage of pregnancy, disease type and duration, and a random error term. Lactation curves using Wood's incomplete gamma function (Wood, 1967) were fit for first, second, and later lactations using data from five Minnesota dairy herds. A decrease in milk production as a result of pregnancy was modeled following Van Arendonk (1985), but the parameters were estimated using data from the five Minnesota herds. The average rate of decline in milk production between d 91 and 305 in lactation was 1.92 $\mathrm{kg} / \mathrm{mo}$.

Cows were culled if they were open after 730 DIM, calved for the 11th time, or had a future profitability of less than $\$ 0$. Future profitability is the expected profit from keeping a cow until her optimal time of replacement compared with replacing her immediately with a calving heifer, taking into account the risk of involuntary culling (Van Arendonk, 1984). Future profitability was calculated with a dynamic programming algorithm as a function of lactation number, DIM, pregnancy status, and level of milk production. A simple adjustment was made for disease status. We assumed that each cow that was culled or died was replaced the following day by a purchased heifer, which calved the day after purchase. All calves were sold the day after they were born. This near-optimal culling policy was preferred over more arbitrary suboptimal culling policies. It also made the longevity and performance of a cow in the herd independent from other cows in the herd.

The voluntary waiting period for first insemination was $50 \mathrm{~d}$ after calving. Every true estrus after the voluntary waiting period had the same probability of being 
detected, equal to EDE. The probability of conception was based on milk yield, DIM, disease type, and insemination number in the current lactation. The average conception rate was 0.4 . Pregnancy diagnosis followed an insemination after $42 \mathrm{~d}$ if estrus was not detected in the cow. Five percent of all pregnancy diagnoses resulted in erroneous conclusions. Embryo loss was included in the probability of conception and timing of return to estrus. Five percent of cows aborted after their pregnancy diagnoses. Cows that were diagnosed open after 365 DIM were kept open until they were culled. The duration of the dry period was $60 \mathrm{~d}$ on average.

Estrus detection ratio was calculated as the number of observed estruses in a period divided by the number of expected estruses in a period times 21 . For example, if five estruses were observed and nine estruses were expected, then EDR was $5 /(9 \times 21)=0.026$. The number of expected estruses times 21 is referred to as the number of estrus days in a period. The number of estrus days was calculated as (the number of cow days after the voluntary waiting period of cows confirmed open + 0.4 times the number of cow days of cows inseminated with insemination result unknown). Every day a cow is in the herd was counted as a cow day. The fraction 0.4 was found to result in observed false alarm rates on control charts that were sufficiently similar to the desired (target) false alarm rates, whereas the more common fraction of (1 - conception rate) resulted in higher false alarm rates than the target (de Vries and Conlin, 2003). Similarly, the number of expected estruses was multiplied by 21 in the denominator of EDR because using only the number of expected estruses could result in much higher false alarm rates than expected.

Net return was calculated as the sum of milk sales and animal sales minus feed cost, heifer purchase costs, and other variable costs. Fixed costs were not included.

Stochastic functions in the model aimed to produce a realistic level of variation in the output from the model. Stochastic elements affected the timing and outcome of reproductive events such as display and observation of estruses, inseminations, abortions, errors in pregnancy diagnosis, and the duration of pregnancy. Daily milk production, occurrence and type of disease, sex and survival of calves born, and cow survival were also affected by stochastic elements. Comparisons with reproductive data from the five Minnesota dairy herds showed that a realistic level of variation in the results of the simulation model was obtained (de Vries, 2001).

\section{Estimation of Permanent and Temporary Effects of a Decrease in Estrus Detection Efficiency}

Twenty-two scenarios were simulated with a herd of 1000 cows. A scenario was defined as a combination of magnitude and duration of a decrease in EDE. A steadystate herd of 1000 cows was simulated for $6020 \mathrm{~d}$ per scenario. The first $2360 \mathrm{~d}$ were used for randomization of the same initial herd to obtain independent herds at the start of $d 2361$ while these herds remained in steady state. Data were collected during the last $3660 \mathrm{~d}$ in periods of $10 \mathrm{~d}$ each. Each scenario was repeated 50 times with independent herds.

In the first four scenarios, EDE was permanently set at $65,55,45$, or $35 \%$ at $d 1$ and remained at those rates until the end of $d 6020$. The permanent estimates of the changes in net return due to a temporary decrease in EDE were calculated from these four scenarios.

Differences in net return per cow per day between $65 \% \mathrm{EDE}$ and permanent rates of 55,45 , or $35 \% \mathrm{EDE}$ were calculated as $\mathrm{B}_{\mathrm{EDE}-65 \%}=\sum_{\mathrm{t}=2361}^{6020}\left(\overline{\mathrm{Y}}_{\mathrm{EDE}, \mathrm{t}}-\overline{\mathrm{Y}}_{65 \%, \mathrm{t}}\right) / 3660$, where $\overline{\mathrm{Y}}_{\mathrm{EDE} \text {, }}$ was the average net returns from days $t$ to $t+10$ at a permanent rate of EDE. The parameter $\mathrm{B}_{\mathrm{EDE}-65 \%}$ then was the difference in net return between $65 \%$ and the lower rate of EDE per cow per day.

In the remaining 18 scenarios, the default EDE was $65 \%$ and was temporarily decreased to 55,45 , or $35 \%$ $\mathrm{EDE}$ at d 2361. The durations of the decreases (T) were $30,60,120,240,480$, or $960 \mathrm{~d}$, after which EDE was immediately reset to $65 \%$ for the remaining days until the end of $d 6020$. The temporary estimates of changes in net return were calculated from these 18 scenarios. The duration of $3660 \mathrm{~d}$ was chosen because preliminary results showed that a temporary decrease in EDE could affect herd performance for several years.

The total change in net return per cow due to a temporary decrease to 55,45 , or $35 \%$ EDE were calculated 6020

as $\sum_{t=2361}^{602} R^{t} \times\left(\bar{V}_{E D E, T, t}-\bar{Y}_{65 \%, t}\right)$, where $\overline{\mathrm{V}}_{\mathrm{EDE}, \mathrm{T}, \mathrm{t}}$ was the average net return from days $t$ to $t+10$ for the scenario with a temporary decrease to the rate EDE during $\mathrm{T}$ $\mathrm{d}$, and $\mathrm{R}^{\mathrm{t}}=(1.07)^{-(\mathrm{t}-2360) / 365.25}$ was the discounting factor at $7 \%$ annual interest. For example, $\overline{\mathrm{V}}_{35 \%, 60,2681}$ was the average of net returns from d 2681 to 2690 for a decrease to $35 \%$ EDE during d 2361 to 2420 . We did not assign a cost to resetting EDE to $65 \%$ after the temporary decrease was ended.

$$
\begin{aligned}
& \text { The objective was to test if } \mathrm{D}_{\mathrm{EDE}, \mathrm{T}}=\sum_{t=2361}^{6020} \mathrm{R}^{\mathrm{t}} \times\left(\bar{V}_{\mathrm{EDE}, \mathrm{T}, \mathrm{t}}\right. \\
& \left.-\bar{Y}_{65 \%, \mathrm{t}}\right)-\sum_{t=2361}^{2360+T} \mathrm{R}^{\mathrm{t}} \times \mathrm{B}_{\mathrm{EDE}-65 \%} \text { equaled } 0 . \text { When the con- }
\end{aligned}
$$

trast $\mathrm{D}_{\mathrm{EDE}, \mathrm{T}}$ was not significantly different from 0 , then the effects of a temporary decrease in EDE could be 
approximated as the constant $\mathrm{B}_{\mathrm{EDE}-65 \%} \times \mathrm{T}$ (ignoring the discounting factor for simplicity).

The variance of $\mathrm{D}_{\mathrm{EDE}, \mathrm{T}}$ is a linear combination of the $\underset{2360+\mathrm{T}}{\operatorname{variances}}$ of the estimates: $\zeta_{\mathrm{EDE}, \mathrm{T}}^{2}=\left(\sigma_{\mathrm{EDE}, \mathrm{T}}^{2}+\sigma_{65 \%, \mathrm{~T}}^{2}\right) / 50$ $+\sum_{\mathrm{t}=2361}\left(\vartheta_{\mathrm{EDE}, \mathrm{t}}^{2}+\vartheta_{65 \%, \mathrm{t}}^{2}\right) / 50$, where $\sigma_{\mathrm{EDE}, \mathrm{T}}^{2}$ was the variance of the sum of discounted net returns at $d 6020$ for a temporary decrease in EDE during $\mathrm{T} d$ and $\vartheta_{\mathrm{EDE}, \mathrm{t}}^{2}$ was the variance of the average discounted net return at day $t$ at the rate of EDE. Satterthwaite's (1946) approximation was used to find the degrees of freedom for $\zeta_{\text {EDE,T }}^{2}$, because the variances of the sums and averages were different. Finally, the $P$-value for each of the 18 $\mathrm{D}_{\mathrm{EDE}, \mathrm{T}}$ using a $t$-test was calculated.

\section{Estimation of Average Time to Signal on Statistical Process Control Charts}

The simulation model was also used to measure the performance of the control charts to detect a decrease in EDE. Eight scenarios of $4520 \mathrm{~d}$ each were simulated with herds of 100 and 1000 cows following the procedure described in de Vries and Conlin (2003). In short, for each scenario, the initial steady state herd was simulated at $65 \%$ EDE for $2000 \mathrm{~d}$ to obtain an independent herd at the start of data collection on d 2001. Next, relevant data were collected for $840 \mathrm{~d}$ to estimate the necessary parameters to set up the control charts at the end of d 2840. Finally, EDE was kept at $65 \%$ or decreased to 55,45 , or $35 \%$ until the end of d 4520 and the time to first signal on each control chart was recorded. Each scenario was replicated 400 times with independent herds. Therefore, these eight scenarios were run more often but for a shorter duration than the 22 scenarios that were used to obtain the permanent and temporary estimates. All other conditions in this and that study were identical.

Shewhart and cusum charts were designed to monitor EDR in each period $j$ (denoted as $p_{j}$ ). Design of control charts implies the choice of the duration of the period, the target ATS (target average time between false alarms), and a probability distribution of the $p_{j}$ observations. For cusum charts, also the change in EDR of most interest must be chosen. Estrous detection ratio was assumed to follow a normal distribution. The duration of each period was set to $7 \mathrm{~d}$ in all cases, except for the Shewhart charts for the 100-cow herd, where the duration of the period was set to $30 \mathrm{~d}$ to obtain a sufficient number of observed estruses in a period. The target ATS was set to 365, 730, or $1095 \mathrm{~d}$.
The center line and control limits for the Shewhart chart were calculated as $\overline{\mathrm{p}} \pm \mathrm{z}_{1-\alpha / 2} \times \mathrm{s}$, where $\overline{\mathrm{p}}$ is the average EDR during the $840 \mathrm{~d}$ of data collection at $65 \%$ EDE and $\mathrm{s}$ is an estimate of the standard error. We used the moving range method to calculate s, which is typical in statistical process control (Montgomery, 1997). Furthermore, $z_{1-\alpha / 2}$ is the $1-\alpha / 2$ probability point of the standard normal distribution, which is the number of standard errors that the control limits deviate from the center line. For the Shewhart chart, it holds that $\alpha$ equals the duration of the period divided by the target ATS. For example, for a period duration of $7 \mathrm{~d}$ and target ATS of $730 \mathrm{~d}, \alpha=7 / 730=0.00959$ and therefore $\mathrm{z}_{1-\alpha / 2}=2.590$. After the Shewhart chart was set $u p, p_{j}$ was plotted for every period and the number of periods until the first $\mathrm{p}_{\mathrm{j}}$ fell outside a control limit was used to calculate the number of days to the first signal for that herd.

The cusum of EDR was calculated as $\mathrm{C}_{j}^{+}=\max (0$, $\mathrm{C}_{\mathrm{j}}^{+}+\mathrm{p}_{\mathrm{j}}-\mathrm{K}^{+}$) for detecting an increase in EDR and $\mathrm{C}_{\mathrm{j}}^{-}$ $=\min \left(0, \mathrm{C}_{\mathrm{j}}^{-}+\mathrm{p}_{\mathrm{j}}-\mathrm{K}^{-}\right)$for detecting a decrease in EDR. Typically, and in this study, $\mathrm{C}_{0}^{+}=\mathrm{C}_{0}^{-}=0$. The reference value $K$ is the midpoint between $\bar{p}$ and the average EDR after a change of most interest. Therefore, the average EDR after a change of most interest must be declared. We used $\mathrm{K}^{+}=1.125 \times \overline{\mathrm{p}}$ and $\mathrm{K}^{-}=0.875 \times \overline{\mathrm{p}}$.

The center line for cusum charts is 0 . The control limits for cusum charts were obtained using the program ANYGETH (Hawkins and Olwell, 1998; available from http://www.stat.umn.edu, School of Statistics, University of Minnesota). $\mathrm{C}_{\mathrm{j}}^{+}$and $\mathrm{C}_{\mathrm{j}}^{-}$were plotted for every period on the cusum chart. The number of periods until the first cusum fell outside one of the cusum control limits was used to calculate the number of days to first signal for that herd.

Figure 1 is an example of the variation in EDR when EDE decreased from 65 to $55 \%$ at the start of wk 121 (d 2841). The Shewhart chart set up at the start of week 121 signaled in week 140 . Therefore, there were (140 $-120) \times 7=140 \mathrm{~d}$ to first signal on the Shewhart chart for this herd. Figure 2 shows the cusum chart for the same data. The time to first signal in this example was $63 \mathrm{~d}$ (9 wk).

The observed ATS was calculated directly as the arithmetic average of the $400 \mathrm{~d}$ to first signal observations if every herd resulted in a signal. If one or more herds failed to signal in $1680 \mathrm{~d}$, then ATS was estimated as the expected value of a Weibull distribution fitted on the ordered distribution of days to first signal using the method of Keats et al. (1997a). The standard error of each observed ATS was approximately equal to $5 \%$ of the ATS because the distribution of days to first signal is approximately exponential. Exponential dis- 


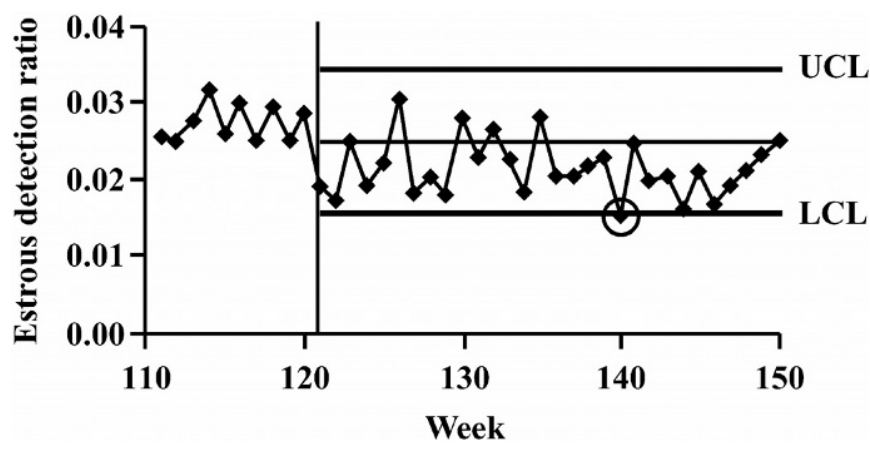

Figure 1. Example of a Shewhart control chart of weekly estrous detection ratios with a decrease in EDE from 65 to 55\% at the start of week 121 . The Shewhart chart is set up at the start of wk 121 and signals for the first time in wk 140. UCL = upper control limit, LCL = lower control limit.

tributions have a standard deviation approximately equal to the mean.

\section{RESULTS}

\section{Effects of Permanently Different Rates of Estrous Detection Efficiency}

Table 1 shows average steady-state results for the 1000-cow herd at four permanently different rates of EDE. Compared with $65 \%$ EDE, lower rates of EDE were associated with higher culling rates, similar milk production, longer intervals to first service and conception, a lower EDR, a decrease in the number of observed estruses, an increase in the number of estrus days, and more days open. Milk production per cow per year remained similar because a higher fraction of cows in lactation compensated for the lower milk production per cow at lower rates of EDE. The calculation of days open included days from culled cows that did not con-

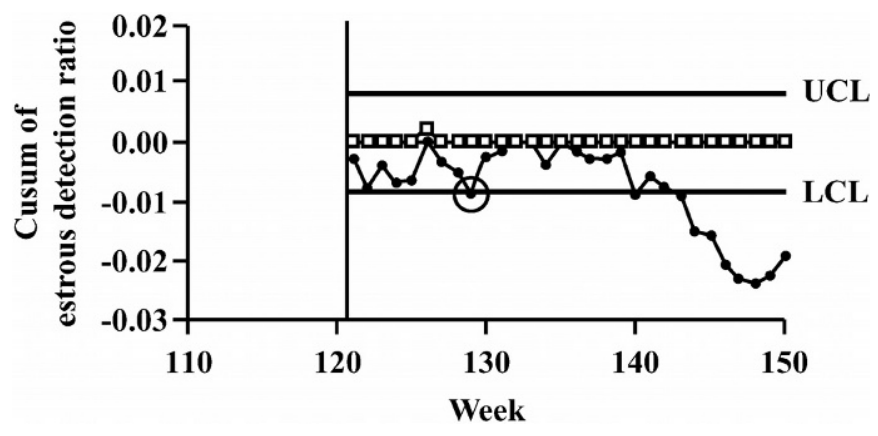

Figure 2. Example of a cusum control chart of weekly estrus detection ratios after a decrease in EDE from 65 to $55 \%$ at the start of wk 121. The cusum chart is set up at the start of wk 121 and signals for the first time in wk 129. UCL = upper control limit, LCL

= lower control limit. ceive, whereas interval to conception included only days from cows that conceived. Calf sales and other costs decreased slightly. All other costs and sales increased with lower rates of EDE.

Net return per cow per year was $\$ 1305.27$ at $65 \%$ EDE and decreased to $\$ 1253.34$ at $35 \%$ EDE. The average losses in net return per cow per year per point decrease from 65 to $55 \%$, from 55 to $45 \%$, and from 45 to $35 \% \mathrm{EDE}$ were $\$ 0.78,1.71$, and 2.71 , respectively. Similarly, the average costs per extra day open were $\$ 0.73,1.13$, and 1.24 , respectively. The difference between 65 and $55 \%$ EDE was a loss in net return of $\$ 0.021$ per cow per day $\left(\mathrm{B}_{55 \%-65 \%}\right)$. Similarly, differences with 45 and $35 \%$ EDE reduced net returns by $\$ 0.068$ $\left(\mathrm{B}_{45 \%-65 \%}\right)$ and $\$ 0.142\left(\mathrm{~B}_{35 \%-65 \%}\right)$ per cow per day.

\section{Effects of a Temporary Decrease in Estrus Detection Efficiency}

Figures 3 through 7 show the average effects of 50 herds of a temporary decrease from 65 to $35 \% \mathrm{EDE}$ during $60 \mathrm{~d}$ on various herd measures. The figures show that the temporary lower rate of EDE caused effects that influenced herd performance for several years.

Estrus detection ratio decreased by approximately 0.013 during this temporary lower rate of EDE, but regained the same rate as before the decrease immediately after resetting EDE to 65\% (Figure 3).

The number of observed estruses decreased immediately and during the entire $60 \mathrm{~d}$ (Figure 4 ) despite the immediate increase in the number of expected estruses (Figure 5). Both the number of observed and expected estruses fluctuated systematically for several years after the end of the $60 \mathrm{~d}$ decrease in EDE. These effects resulted from an increase in the numbers of open cows due to the temporary decrease in EDE. When EDE returned to $65 \%$, this large group of open cows resulted in a larger number of new pregnancies. As a result, the number of open cows decreased and the number of pregnant cows increased. After about 9 mo, this large group of pregnant cows calved, thus increasing the number of open cows again. This cycle repeated itself but faded out after several years due to random outcomes of reproductive events and cow replacement.

The effects of a decrease in EDE on milk production (Figure 6) corresponded to the changes in the number of pregnancies and the numbers of lactating and dry cows over time (not shown). Because open cows were less likely to be inseminated during the temporary decrease, fewer cows became pregnant and therefore fewer cows were dried off after 7 mo after the start of the temporary decrease. Consequently, total herd milk production increased after those 7 mo because more cows were still lactating. Because more cows became 
Table 1. Average steady state results for the 1000-cow herd at four permanent rates of estrous detection efficiency.

\begin{tabular}{|c|c|c|c|c|}
\hline \multirow[b]{2}{*}{ Herd measure } & \multicolumn{4}{|c|}{ Estrous detection efficiency ${ }^{1}$} \\
\hline & $65 \%$ & $55 \%$ & $45 \%$ & $35 \%$ \\
\hline Annual culling rate & 0.21 & 0.22 & 0.24 & 0.28 \\
\hline Milk weight/cow/yr $\left(10^{3} \mathrm{~kg}\right)$ & 10.36 & 10.36 & 10.36 & 10.36 \\
\hline Cows in milk (\%) & 87.3 & 87.9 & 88.7 & 89.8 \\
\hline Interval to first service (d) & 73.3 & 79.4 & 87.7 & 99.0 \\
\hline Interval to conception (d) & 123.5 & 130.1 & 136.9 & 144.4 \\
\hline Conception rate & 0.40 & 0.41 & 0.42 & 0.43 \\
\hline Observed estruses/cow/yr & 2.20 & 2.06 & 1.86 & 1.61 \\
\hline Estrus days/cow/yr & 85.7 & 96.4 & 111.9 & 134.5 \\
\hline Estrus detection ratio & 0.026 & 0.021 & 0.017 & 0.012 \\
\hline Days open/cow/yr & 135.9 & 146.5 & 161.6 & 183.5 \\
\hline Calf sales/cow/yr (\$) & 92.49 & 90.28 & 87.74 & 84.40 \\
\hline Cow sales/cow/yr $(\$)$ & 81.54 & 86.74 & 97.71 & 115.70 \\
\hline Milk sales/cow/yr (\$) & 2936.08 & 2940.16 & 2945.22 & 2956.94 \\
\hline Feed costs/cow/yr $(\$)$ & 1133.97 & 1136.63 & 1140.13 & 1145.81 \\
\hline Heifer purchase cost/cow/yr (\$) & 273.06 & 287.42 & 317.35 & 367.84 \\
\hline Other costs/cow/yr $(\$)$ & 398.05 & 395.90 & 393.06 & 389.36 \\
\hline Net return/cow/yr (\$) & 1305.27 & 1297.48 & 1280.40 & 1253.34 \\
\hline
\end{tabular}

${ }^{1}$ The standard error is at most $0.3 \%$ of the average, but often significantly less.

pregnant after the end of the temporary decrease, milk production decreased again when this large pregnant group went dry. Changes in net return (Figure 7) were highly correlated with changes in milk production.

Similar graphs for all scenarios showed that the herds had returned to steady state in about $7 \mathrm{yr}$ for all magnitudes and durations of the temporary decreases in EDE considered in our study. Larger and longer temporary decreases took longer to return the herd to steady state. We included all net returns for $10 \mathrm{yr}(3660$ d) after the start of the temporary decrease in EDE, to make sure all delayed effects were accounted for (Figure 8).

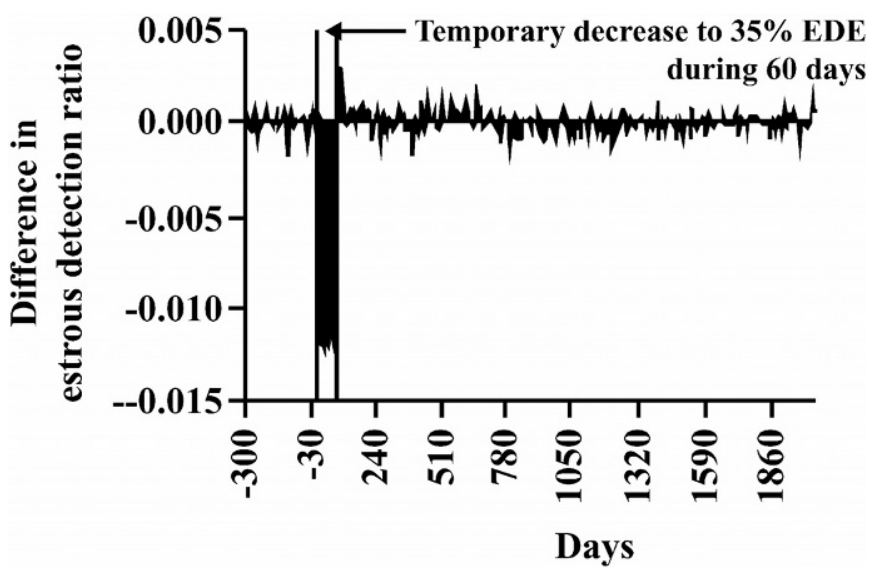

Figure 3. Effect of a decrease from 65 to $35 \%$ EDE during $60 \mathrm{~d}$ on estrus detection ratio over time (averages of 50 herds of 1000 cows each).
Table 2 shows the permanent and temporary estimates of the total changes in net return per cow at the end of $3660 \mathrm{~d}$. For example, the temporary estimate of a decrease to $35 \%$ EDE during $60 \mathrm{~d}$ was a loss in net return of $\$ 0.62 \pm \$ 7.59$. The permanent estimate was a loss of $\$ 8.50 \pm \$ 0.20$. However, the difference, a loss of $\$ 0.62-\$ 8.50=-\$ 7.88$, was not significantly different from $0(P=0.151)$. Therefore, the permanent estimate was accepted in this case.

The results further show that the temporary estimates of the decreases in EDE were occasionally positive, meaning an increase in total net return. This positive effect was clearer for short temporary decreases in

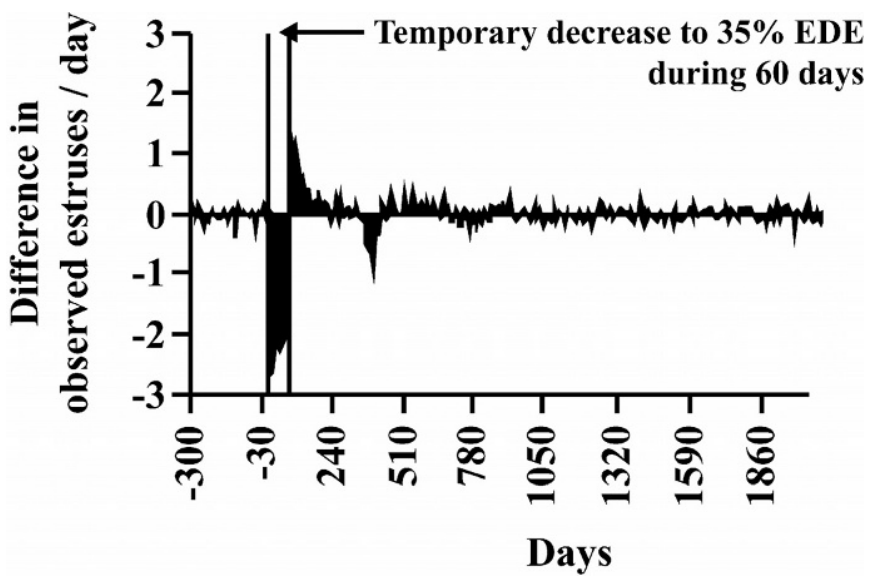

Figure 4. Effect of a decrease from 65 to $35 \%$ EDE during $60 \mathrm{~d}$ on the number of observed estruses per day over time (averages of 50 herds of 1000 cows each). 


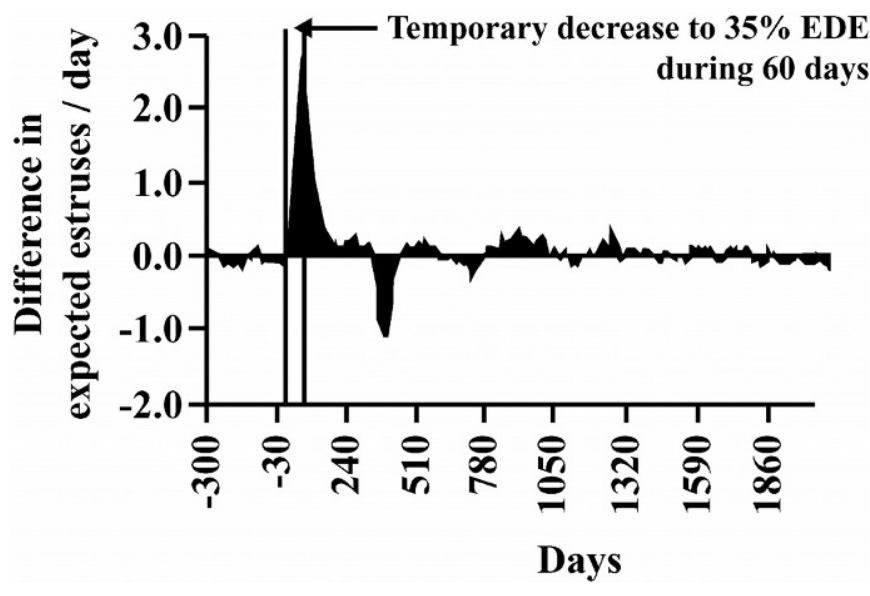

Figure 5. Effect of a decrease from 65 to 35\% EDE during $60 \mathrm{~d}$ on the number of expected estruses per day over time (averages of 50 herds of 1000 cows each).

EDE and significant for all temporary decreases during $120 \mathrm{~d}$, regardless of the magnitude of the decrease. Long temporary decreases resulted generally in a loss in net return per cow. The temporary estimate of the change in net return per cow was higher than the permanent estimate in 17 scenarios. This difference was significant in eight scenarios $(P<0.01)$.

\section{Average Time to Signal and Total Loss in Net Return}

The observed ATS for decreases to 55, 45, and 35\% EDE with the Shewhart and cusum charts for three target rates of false alarms are shown in Table 3 . The observed ATS at $65 \%$ EDE (observed number of days between false alarms) were occasionally significantly

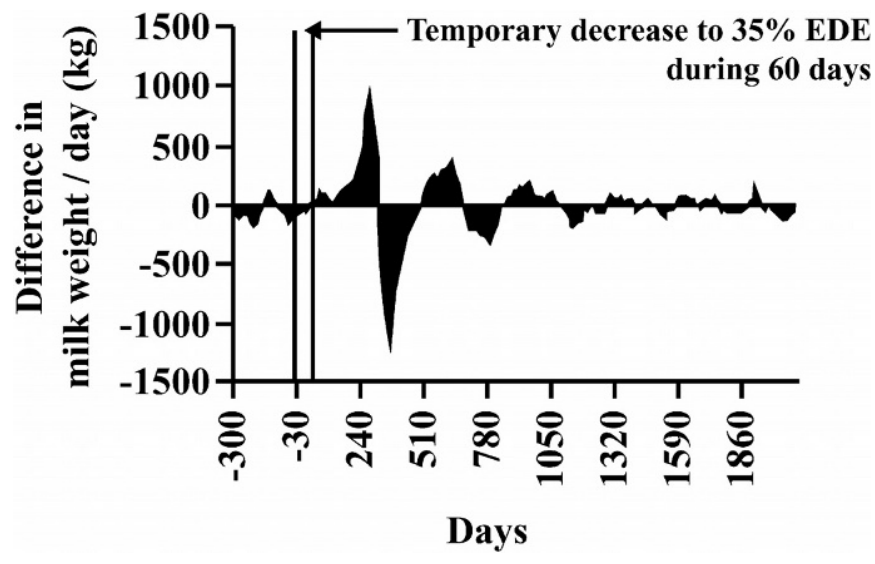

Figure 6. Effect of a decrease from 65 to 35\% EDE during $60 \mathrm{~d}$ on milk production per day over time (averages of 50 herds of 1000 cows each).

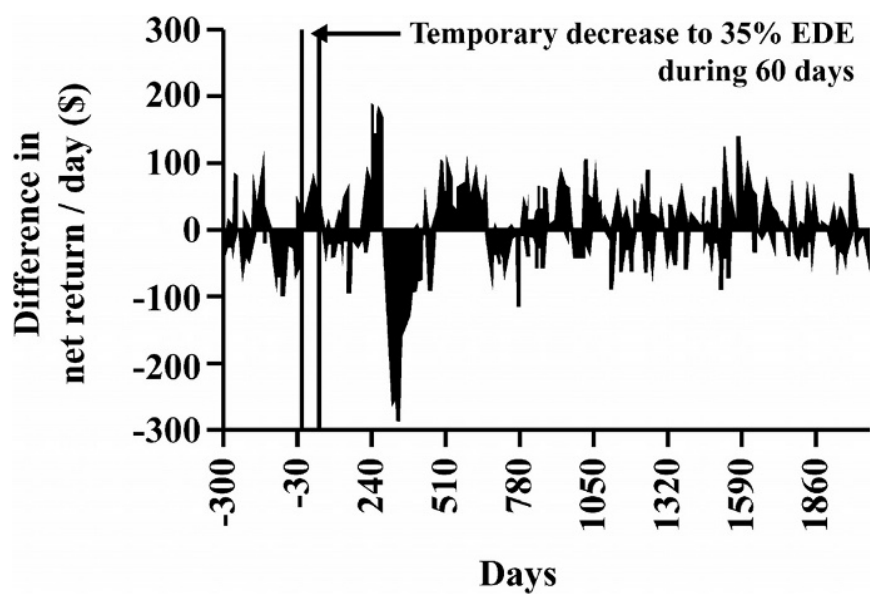

Figure 7. Effect of a decrease from 65 to $35 \%$ EDE during 60 $d$ on net return per day over time (averages of 50 herds of 1000 cows each).

different from the target ATS (desired number of days between false alarms), especially for the 100-cow herd. For example, the observed average time between false alarms was $439 \mathrm{~d}$, whereas the target was $730 \mathrm{~d}$. This result followed primarily from the observation that EDR was not exactly normally distributed.

As expected, a decrease in EDE was signaled earlier in the 1000-cow herd than in the 100-cow herd. A decrease to $35 \%$ EDE was typically detected in 41 to 68 $\mathrm{d}$ for the 100-cow herd and 8 to $11 \mathrm{~d}$ for the 1000-cow herd, depending on the target ATS. Larger decreases were signaled earlier than smaller decreases. A longer target ATS resulted in a longer observed ATS. Decreases to 55\% EDE were typically signaled earlier with a cusum chart than with a Shewhart chart.

Because the distribution of days to first signal observations is approximately exponential, the days to first signal were shorter than the ATS in the majority of the 400 simulated herds. This implied that the estimate of the total change in net return was highly dependent on the estimated change in net return for temporary decreases during a short time. Moreover, the temporary estimates of the changes in net return were only consistently significantly different from the permanent estimates for larger and longer temporary decreases in EDE. Because larger decreases in EDE were associated with shorter ATS, the estimates for the longer temporary decreases (480 d, $960 \mathrm{~d}$ ) for a large decrease in EDE (to $35 \%$ ) were not relevant. Therefore, the total changes in net return were calculated with the permanent estimates as $\mathrm{B}_{\mathrm{EDE}-65 \%} \times$ observed ATS. For example, if the decrease to 55\% EDE lasted on average 208 $\mathrm{d}$ until detected with a Shewhart chart, then the total change in net return was a loss of $\$ 0.021 \times 208=\$ 4.44$ per cow. 


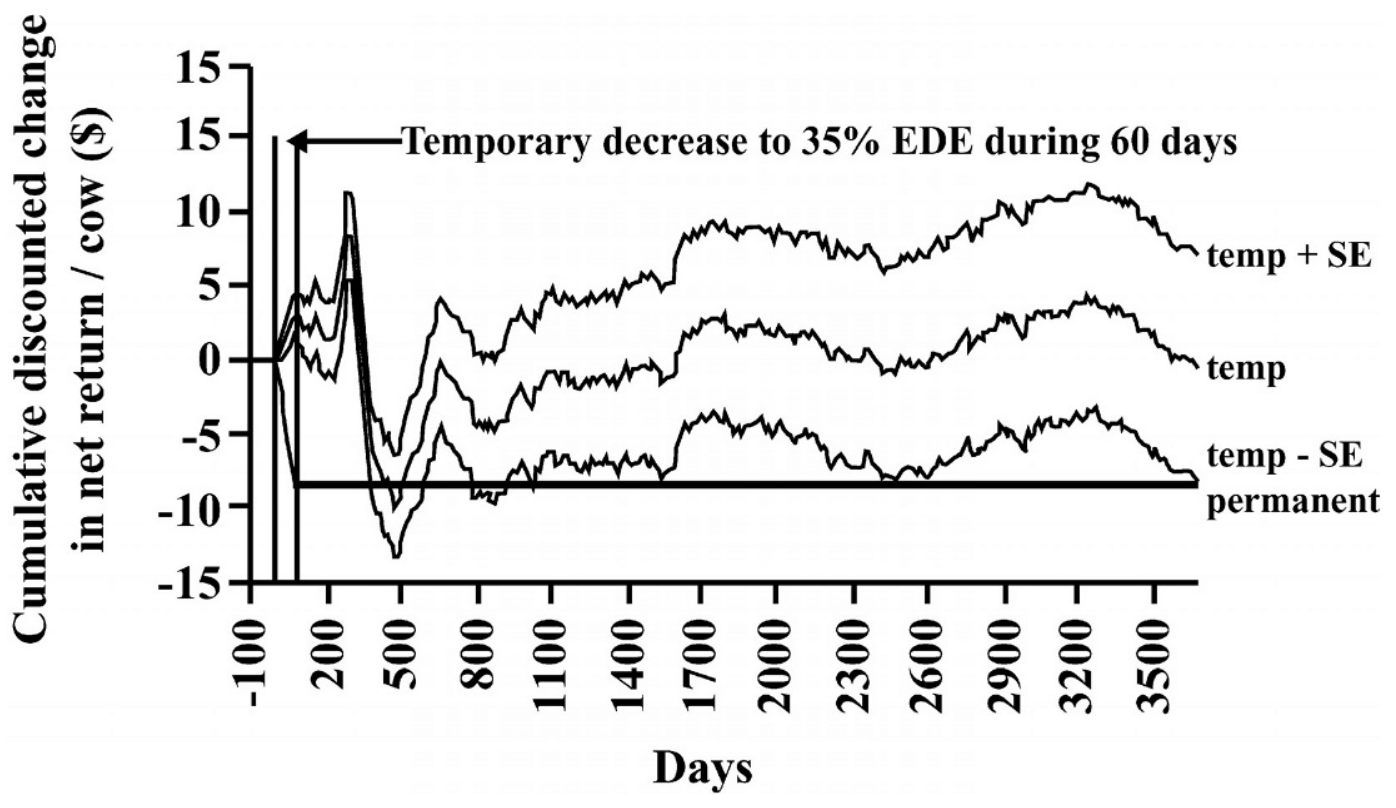

Figure 8. Cumulative discounted changes in net return per cow in $3660 \mathrm{~d}$ following the start of a decrease from 65 to $35 \%$ EDE during $60 \mathrm{~d}$ (averages of 50 herds of 1000 cows each). Displayed are the mean of the temporary estimate ("temp"), its standard error (SE), and the mean of the permanent estimate ("permanent") of the total change in net return per cow. The temporary estimate at $3660 \mathrm{~d}$ is $-\$ 0.62 \pm$ $\$ 7.59$ and the permanent estimate is $-\$ 8.50 \pm \$ 0.20$.

For the 100-cow herd, the total loss in net return per cow was between $\$ 4.44$ (target ATS was $365 \mathrm{~d}$ ) and $\$ 12.53$ (target ATS was $1095 \mathrm{~d}$ ) for all 18 scenarios. The type of control charts used (Shewhart or cusum) did not have much effect on the total change in net return. In general, larger decreases with higher losses per day were compensated by earlier detection of the temporary lower rates of EDE.

Table 2. Total discounted change in net return per cow (\$) at the end of $3660 \mathrm{~d}$ for temporary and permanently different rates from $65 \%$ estrus detection efficiency (EDE) during $\mathrm{T}$ d.

\begin{tabular}{|c|c|c|c|c|c|c|}
\hline EDE & $\begin{array}{l}\text { Days } \\
(\mathrm{T})\end{array}$ & $\begin{array}{l}\text { Temporary } \\
\text { estimate }^{1}\end{array}$ & $\begin{array}{l}\text { Permanent } \\
\text { estimate }^{2}\end{array}$ & $\begin{array}{l}\text { Temporary - } \\
\text { permanent } \\
\text { estimate }\end{array}$ & $\begin{array}{l}\text { Degrees of } \\
\text { freedom }\end{array}$ & $P$-value ${ }^{3}$ \\
\hline $55 \%$ & 30 & $6.95 \pm 8.05$ & $-0.64 \pm 0.08$ & $7.59 \pm 8.05$ & 99.0 & 0.174 \\
\hline $55 \%$ & 60 & $8.46 \pm 8.11$ & $-1.27 \pm 0.16$ & $9.73 \pm 8.11$ & 98.1 & 0.117 \\
\hline $55 \%$ & 120 & $17.89 \pm 7.50$ & $-2.53 \pm 0.32$ & $20.42 \pm 7.51$ & 98.4 & 0.004 \\
\hline $55 \%$ & 240 & $-7.95 \pm 8.56$ & $-5.01 \pm 0.64$ & $-2.93 \pm 8.58$ & 99.1 & 0.367 \\
\hline $55 \%$ & 480 & $5.76 \pm 7.25$ & $-9.81 \pm 1.25$ & $15.57 \pm 7.36$ & 103.8 & 0.018 \\
\hline $55 \%$ & 960 & $-10.57 \pm 7.33$ & $-18.78 \pm 2.39$ & $8.21 \pm 7.71$ & 118.6 & 0.145 \\
\hline $45 \%$ & 30 & $7.84 \pm 8.51$ & $-2.04 \pm 0.09$ & $9.88 \pm 8.51$ & 98.0 & 0.124 \\
\hline $45 \%$ & 60 & $3.32 \pm 7.93$ & $-4.07 \pm 0.18$ & $7.39 \pm 7.93$ & 98.1 & 0.177 \\
\hline $45 \%$ & 120 & $14.82 \pm 7.67$ & $-8.09 \pm 0.35$ & $22.92 \pm 7.68$ & 98.4 & 0.002 \\
\hline $45 \%$ & 240 & $-10.61 \pm 7.66$ & $-16.01 \pm 0.70$ & $5.40 \pm 7.69$ & 99.6 & 0.242 \\
\hline $45 \%$ & 480 & $-6.71 \pm 8.08$ & $-31.32 \pm 1.37$ & $24.61 \pm 8.20$ & 103.4 & 0.002 \\
\hline $45 \%$ & 960 & $-38.39 \pm 8.23$ & $-59.97 \pm 2.61$ & $21.58 \pm 8.64$ & 117.6 & 0.007 \\
\hline $35 \%$ & 30 & $2.00 \pm 8.53$ & $-4.26 \pm 0.10$ & $6.26 \pm 8.53$ & 98.0 & 0.233 \\
\hline $35 \%$ & 60 & $-0.62 \pm 7.59$ & $-8.50 \pm 0.20$ & $7.88 \pm 7.59$ & 98.1 & 0.151 \\
\hline $35 \%$ & 120 & $7.37 \pm 7.96$ & $-16.90 \pm 0.38$ & $24.27 \pm 7.97$ & 98.4 & 0.001 \\
\hline $35 \%$ & 240 & $-4.75 \pm 8.44$ & $-33.43 \pm 0.75$ & $28.68 \pm 8.48$ & 99.6 & $<0.001$ \\
\hline $35 \%$ & 480 & $-28.93 \pm 7.91$ & $-65.40 \pm 1.47$ & $36.47 \pm 8.04$ & 104.8 & $<0.001$ \\
\hline $35 \%$ & 960 & $-94.09 \pm 8.44$ & $-125.24 \pm 2.82$ & $31.15 \pm 8.90$ & 119.6 & $<0.001$ \\
\hline
\end{tabular}

${ }^{1}$ Present value of the actual change in total net return during $3660 \mathrm{~d}$.

${ }^{2}$ Present value of the calculated change in total net return during $\mathrm{T}$ days. The permanent estimate is calculated as the change in net return per day $\left(\mathrm{B}_{\mathrm{EDE}-65 \%}\right)$ times the duration of the temporary decrease $(\mathrm{T})$.

${ }^{3} P$-value calculated using degrees of freedom rounded to next integer. 
Table 3. Observed average time to signal (ATS) and total change in net return per cow ( $\Delta$ NR) for decreases to 55, 45, and 35\% estrus detection efficiency (EDE) for the Shewhart and cusum control charts applied to estrous detection ratio.

\begin{tabular}{|c|c|c|c|c|c|c|c|}
\hline \multirow{2}{*}{$\begin{array}{l}\text { Control } \\
\text { Chart }\end{array}$} & \multirow[b]{2}{*}{$\mathrm{EDE}$} & \multicolumn{2}{|c|}{ Target ATS is $365 \mathrm{~d}$} & \multicolumn{2}{|c|}{ Target ATS is $730 \mathrm{~d}$} & \multicolumn{2}{|c|}{ Target ATS is $1095 \mathrm{~d}$} \\
\hline & & $\operatorname{ATS}(\mathrm{d})$ & $\Delta \mathrm{NR}$ & $\operatorname{ATS}(\mathrm{d})$ & $\Delta \mathrm{NR}$ & $\operatorname{ATS}(d)$ & $\Delta \mathrm{NR}$ \\
\hline & & & & -100 cows & & & \\
\hline \multirow{4}{*}{ Shewhart ${ }^{1}$} & $65 \%$ & $290^{*}$ & & $439 *$ & & $592^{*}$ & \\
\hline & $55 \%$ & 208 & $-\$ 4.44$ & 375 & $-\$ 8.00$ & 549 & $-\$ 11.71$ \\
\hline & $45 \%$ & 83 & $-\$ 5.65$ & 132 & $-\$ 8.99$ & 184 & $-\$ 12.53$ \\
\hline & $35 \%$ & 41 & $-\$ 5.83$ & 50 & $-\$ 7.11$ & 63 & $-\$ 8.96$ \\
\hline \multirow{4}{*}{ Cusum $^{2}$} & $65 \%$ & 341 & & $528^{*}$ & & $635^{*}$ & \\
\hline & $55 \%$ & 253 & $-\$ 5.40$ & 348 & $-\$ 7.42$ & 415 & $-\$ 8.85$ \\
\hline & $45 \%$ & 88 & $-\$ 5.99$ & 113 & $-\$ 7.70$ & 127 & $-\$ 8.65$ \\
\hline & $35 \%$ & 48 & $-\$ 6.83$ & 60 & $-\$ 8.54$ & 68 & $-\$ 9.67$ \\
\hline \multirow[t]{4}{*}{ Shewhart ${ }^{2}$} & $65 \%$ & $502^{*}$ & & $904^{*}$ & & 1250 & \\
\hline & $55 \%$ & 146 & $-\$ 3.11$ & 317 & $-\$ 6.76$ & 489 & $-\$ 10.43$ \\
\hline & $45 \%$ & 19 & $-\$ 1.29$ & 31 & $-\$ 2.11$ & 44 & $-\$ 3.00$ \\
\hline & $35 \%$ & 8 & $-\$ 1.14$ & 9 & $-\$ 1.28$ & 10 & $-\$ 1.42$ \\
\hline \multirow{4}{*}{ Cusum $^{2}$} & $65 \%$ & 422 & & 735 & $\ldots$ & 1020 & \\
\hline & $55 \%$ & 56 & $-\$ 1.19$ & 69 & $-\$ 1.47$ & 83 & $-\$ 1.77$ \\
\hline & $45 \%$ & 14 & $-\$ 0.95$ & 16 & $-\$ 1.09$ & 18 & $-\$ 1.23$ \\
\hline & $35 \%$ & 9 & $-\$ 1.28$ & 10 & $-\$ 1.42$ & 11 & $-\$ 1.57$ \\
\hline
\end{tabular}

${ }^{1}$ Period duration is $30 \mathrm{~d}$.

${ }^{2}$ Period duration is $7 \mathrm{~d}$.

*Observed ATS (for EDE $=65 \%)$ differed $(P<0.001)$ from respective target ATS of 365, 730, or $1095 \mathrm{~d}$.

The loss in net return for the 1000-cow herd was the lowest for the largest decrease (35\% EDE) if only the Shewhart chart was used. The minimum loss in this case was $\$ 1.14$ per cow (target ATS was $365 \mathrm{~d}$ ). Thus, smaller decreases in EDE were more costly because of the extra time needed to detect the decrease. If a cusum chart was used, the losses were the lowest for the decrease to $45 \%$ EDE with a minimum loss of $\$ 0.95$ per cow (target ATS was $365 \mathrm{~d}$ ). The losses for the decreases to 55 and $35 \%$ EDE were similar and $\$ 0.24$ to 0.54 greater per cow than the loss at $45 \%$ EDE.

Due to earlier detection of the smaller decreases in EDE, the losses in net return incurred in the 1000-cow herd when cusum charts were used were in general considerably less than the losses when Shewhart charts were used. For a decrease to $55 \%$ EDE, the economic value of the earlier detection with the cusum chart compared to the Shewhart chart ranged from $\$ 1.92$ to $\$ 8.66$ per cow, depending again on the target rate of false alarms.

\section{DISCUSSION}

The first objective of this study was to compare the temporary estimates of changes in net return due a temporary decrease in EDE with the permanent estimates derived from permanently different rates in EDE. The changes in the technical and economic results at lower permanent rates of EDE were in agreement with other results (Oltenacu et al., 1981; Marsh et al., 1987; Dijkhuizen and Stelwagen, 1988; Pecsok et al., 1994; Plaizier et al., 1998). Reproductive efficiency was reduced, and consequently net return was lower. Decreases in EDE had greater economic consequences at lower EDE rates, ranging from approximately $\$ 0.78$ to 2.71 per cow per year per point decrease in EDE, which is in agreement with Marsh et al. (1987), and Pecsok et al. (1994). The costs per extra day open, ranging from $<\$ 0.73$ to $>\$ 1.24$ per cow, were also within the range of previously reported results (Plaizier et al., 1997). Clearly, these estimates vary in practice, depending on cow performance, prices, and management such as culling policy.

The effects of the temporary decreases in EDE lasted for several years until they faded out due to variation in reproductive events and culling. We did not formally test when the herd was back in steady state, but graphs such as Figures 3 to 8 showed that $3660 \mathrm{~d}$ after the start of the temporary decrease in EDE was sufficient for all scenarios.

The temporary estimates varied considerably from herd to herd. This indicated that the effects of a temporary decrease in EDE were difficult to predict precisely. The precision of the average expected effects would improve with more herds or larger herd sizes, but each scenario took considerable time and effort to simulate. The application of variance reduction techniques might have reduced the variance of estimates (Hillier and 
Lieberman, 2001). However, herds needed to be independent to obtain independent measures of days to first signal on control charts. If herds were dependent, then the observed ATS would be biased.

The temporary estimates of the change in net return were typically higher than the permanent estimates, although the differences were not consistently significant. It is not clear why the decrease during $120 \mathrm{~d}$ resulted in significant positive temporary estimates. These average estimates were the result of complex herd dynamics. For example, a temporary decrease in EDE may not as severely affect reproductive culling because a good chance exists that a cow gets pregnant before she becomes a reproductive cull, even though she would conceive later in lactation. The permanent estimate included a higher reproductive cull rate, regardless of the duration of the decrease in EDE. Our culling policy was near optimal at a rate of $65 \% \mathrm{EDE}$ given the assumptions (e.g., immediate replacement with a calving heifer). We did not find other studies that estimated the effects of temporary decreases in EDE.

Performance of the control charts for different values of the parameters of the simulation model in this study were not evaluated. In a previous study (de Vries and Conlin, 2003), a nonoptimal culling strategy based on culling cows when home-raised heifers entered the herd resulted in similar observed ATS for the same decreases in EDE. In addition, higher conception rates resulted in later detection of decreases in EDE due to a smaller group of open cows that is subject to continual detection of estrus.

The decrease in EDE affected the probability of detection of all true estruses equally. Temporary decreases in EDE were arbitrarily modeled as simple step changes. The effects of many realistic changes in EDE can be evaluated with our modeling approach. If only a subgroup of cows was affected by lower EDE, then the losses in net return might be different per affected cow. For example, if EDE was reduced in early lactation only, but the duration to detect the decrease was the same, then total losses in net return might be less because the costs of extra days open early in lactation are lower than later in lactation (Holmann et al., 1984).

Our second objective was to estimate the total changes in net return associated with temporary decreases in EDE that lasted until detected with control charts. Because an investigation of the sources causing the variation in EDR after a signal on a control chart typically costs time and money (for example, whether detection of estrus is performed as intended), sufficient evidence must exist that EDR has really changed before an investigation is warranted economically. Thus, false alarms have a cost and are not desired. However, control charts designed for lower false alarm rates allow true decreases in EDE to continue longer. Therefore, there is also a cost associated with too few false alarms. The optimal rate of false alarms, and therefore the most economic placement of the control limits, could be calculated if the cost of the investigation was available (see for example Keats et al., 1997b; Montgomery, 1997), but such costs are typically difficult to obtain.

The control charts applied in this study were designed for normally distributed observations, but because EDR was not exactly normally distributed, the observed false alarm rates were in five of the 12 cases significantly different from their targets. Control charts designed for other distributions might result in observed false alarm rates closer to their targets, although the use of control charts based on a binomial model for EDR did not improve the observed false alarm rates (de Vries and Conlin, 2003). Because the observed false alarm rates differed among the scenarios, the total changes in net return could only be fairly compared within a given combination of control chart, herd size, and target rate of false alarms.

As expected, larger decreases in EDE were signaled earlier with control charts. This result is in agreement with the expected performance of control charts (Montgomery, 1997). Although larger decreases were more expensive per day, earlier detection generally resulted in an equal to smaller total loss in net return.

If a constant loss for any marginal decrease in EDE was assumed, then larger decreases in EDE resulted in fewer losses than smaller decreases for all designs of control charts in this study. For example, if the cost per cow per year was $\$ 5$ per point decrease in EDE, and a Shewhart control chart with a target ATS of 730 $\mathrm{d}$ was used in a 100-cow herd, decreases to respectively 55,45 , or $35 \%$ EDE would cost $\$ 51.37,36.16$, or 20.55 per cow.

The results with the 1000-cow herd showed that it could be economically important to use cusum charts to detect smaller decreases in EDE. Shewhart charts may signal large decreases earlier than cusum charts in some situations (Montgomery, 1997), but this was not obvious from our results. Shewhart charts are well known and simple to set up. Therefore, they are generally part of any implementation of control charts (Montgomery, 1997). Our results affirm the suggestion that both Shewhart and cusum charts should be used together (Woodall, 2000).

\section{CONCLUSIONS}

Effects due to a temporary decrease in EDE could affect herd performance for several years before they disappeared. Temporary estimates of the change in net return were not consistently significantly different from 
permanent estimates of the same magnitude and duration of a decrease in the rate of EDE. However, some evidence exists that effects on net return due to temporary decreases may be smaller than the permanent estimates suggest.

Control charts signaled larger decreases in EDE much earlier than smaller decreases. Earlier detection compensated for the higher losses in net return per day. Thus larger decreases were not more costly than smaller decreases. Cusum charts detected small decreases in EDE occasionally much earlier than the Shewhart charts, thereby reducing the total loss caused by the decrease in EDE considerably. These results confirm that the use of cusum charts should be considered in addition to the use of Shewhart charts to detect small decreases in EDE as early as possible.

\section{REFERENCES}

de Vries, A. 2001. Statistical process control charts applied to dairy herd reproduction. Ph.D. Diss., Univ. of Minnesota, St. Paul.

de Vries, A., and B. J. Conlin. 2003. Design and performance of statistical process control charts applied to estrous detection efficiency. J. Dairy Sci. 86:1970-1984.

Dijkhuizen, A. A., and J. Stelwagen. 1988. An economic comparison of four insemination and culling policies in dairy herds, by method of stochastic simulation. Livest. Prod. Sci. 18:239-252.

Hawkins, D. M., and D. H. Olwell. 1998. Cumulative Sum Charts and Charting for Quality Improvement. Springer-Verlag, New York.

Hillier, F. S., and G. J. Lieberman. 2001. Introduction to Operations Research. 7th ed. McGraw-Hill, New York, NY.

Holmann, F. J., C. R. Shumway, R. W. Blake, R. B. Schwart, and E. M. Sudweeks. 1984. Economic value of days open for Holstein cows of alternative milk yields with varying calving intervals. J. Dairy Sci. 67:636-643.
Keats, J. B., F. P. Lawrence, and F. K. Wang. 1997a. Weibull maximum likelihood parameter estimates with censored data. J. Qual. Technol. 29:105-110.

Keats, J. B., E. Del Castillo, E. von Collani, and E. M. Saniga. 1997b. Economic modeling for statistical process control. J. Qual. Technol. 29:114-147.

Marsh, W. E., A. A. Dijkhuizen, and R. S. Morris. 1987. An economic comparison of four culling decision rules for reproductive failure in United States dairy herds using DairyORACLE. J. Dairy Sci. 70:1274-1280.

Montgomery, D. C. 1997. Introduction to Statistical Quality Control. 3rd ed., John Wiley and Sons, New York, NY.

Oltenacu, P. A., T. R. Rounsaville, R. A. Milligan, and R. H. Foote. 1981. Systems analysis for designing reproductive management programs to increase production and profit in dairy herds. J. Dairy Sci. 64:2096-2104.

Pecsok, S. R., M. L. McGilliard, and R. L. Nebel. 1994. Conception rates. 1. Derivation and estimates for effects of estrus detection on cow profitability. J. Dairy Sci. 77:3008-3015.

Plaizier, J. C. B., G. J. King, J. C. M. Dekkers, and K. Lissemore. 1997. Estimation of economic values of indices for reproductive performance in dairy herds using computer simulation. J. Dairy Sci. 80:2775-2783.

Plaizier, J. C. B., G. J. King, J. C. M. Dekkers, and K. Lissemore. 1998. Modeling the relationship between reproductive performance and net-revenue in dairy herds. Agric. Sys. 56:305-322.

Satterthwaite, F. E. 1946. An approximate distribution of estimates of variance components. Biometrics Bull. 2:110-114.

Spahr, S. L. 1993. New technologies and decision making in high producing herds. J. Dairy Sci. 76:3269-3277.

Van Arendonk, J. A. M. 1984. Studies on the replacement policies in dairy cattle I. Evaluation of techniques to determine the optimum time for replacement and to rank cows on future profitability. Z. Tierz. Zuechtungsbiol. 101:330-340.

Van Arendonk, J. A. M. 1985. A model to estimate the performance, revenues and costs of dairy cows under different production and price situations. Agric. Systems 16:157-189.

Wood, P. D. P. 1967. Algebraic model of the lactation curve in cattle. Nature 216:164-165.

Woodall, W. H. 2000. Controversies and contradictions in statistical process control. J. Qual. Technol. 32:341-350. 